\title{
APROXIMACIÓN AL ESTUDIO DE LOS SUPUESTOS DE RESPONSABILIDAD DE LOS DIRECTORES DE LAS SOCIEDADES ANÓNIMAS
}

\section{Oswaldo Hundskopf Exebio}

Profesor de la Facultad de Derecho y de la Maestria de Derecho Empresarial de la Universidad de Lima.

A propósito de un debate suscitado entre los miembros de un tribunal arbitral en el contexto de un proceso en marcha, nos surgió la inquietud por conocer con claridad los alcances y límites de la responsabilidad que asumen quienes integran el directorio de una sociedad anónima, y de identificar, como consecuencia de ello, todos los supuestos en los cuales expresa o tácitamente se deriva algún tipo de responsabilidad para quienes son miembros de dicho órgano social.

Al respecto, no es primera vez que escuchamos que se plantea la tesis por la cual la misma responsabilidad limitada de quienes son accionistas de una sociedad anónima y que alcanza hasta el monto de sus aportes, debería hacerse extensiva (y por ello debería también proteger) a quienes son directores (elegidos para representar a la propia sociedad) y que, por tanto, viene a ser injusto que en la actual Ley General de Sociedades existan algunos supuestos específicos en los cuales los directores asumen responsabilidad personal, solidaria e ilimitada, a diferencia de la responsabilidad limitada que asumen quienes son sólo accionistas.

El tema parece simple, pero en realidad no lo es, ya que surgen una serie de implicancias que es importante tomar en cuenta antes de pasar a comentar específicamente cada uno de los supuestos de responsabilidad establecidos en la Ley General de Sociedades (ley 26887, en lo sucesivo LGS): 
- Suele suceder que, en algunos casos, personas naturales que son accionistas de la sociedad son a la vez directores de la misma, y en tales casos, en nuestra opinión, aparecen dos diferentes escenarios en cuanto a su responsabilidad: por un lado, como titulares de las acciones, responden de manera limitada, únicamente hasta el monto de sus aportes; por otro, respecto específicamente a la función de director, responden en forma personal, y en algunas situaciones en forma solidaria e ilimitada, como en los casos que están expresa o tácitamente establecidos en la LGS. Ello se explica en razón de que hay una sustancial diferencia con relación a la causa generadora de la responsabilidad, en el sentido de que en el primero de los escenarios hay un riesgo inherente a la inversión de capital materializada al consumarse y perfeccionarse los aportes, y en el segundo se supone que quienes son elegidos directores han aceptado expresa o tácitamente el cargo, y por tanto sus nombramientos obran inscritos en las respectivas fichas registrales de las sociedades anónimas. Entendemos, en consecuencia, que sus designaciones se han producido en razón de que, supuestamente, reúnen las condiciones y calidades personales necesarias para integrar un cargo eminentemente técnico, ya que el directorio tendrá a su cargo la administración y gestión de la sociedad dentro de su objeto, debiendo cada director desempeñar el cargo con la diligencia de un ordenado comerciante y de un representante leal, conforme lo preceptúa el primer párrafo del artículo 171 de la LGS.

- Existe además, en nuestra opinión, un criterio errado en el sentido de que, en algunos casos, quienes son elegidos directores de una sociedad anónima consideran que deben mantener una especie de cordón umbilical con los accionistas o con la clase de acciones a los que deben su elección, y que por tanto deben mantener una suerte de lealtad y fidelidad frente a ellos y proteger sus intereses. Sobre el particular, consideramos que una vez que se formaliza y perfecciona la elección e integración del directorio se rompe dicho vínculo, de forma tal que los directores, cualquiera que sea el grupo de accionistas o la clase de acciones que los eligió, deben actuar con plena independencia y contribuir con su experiencia y capacidad a la adopción de decisiones, en función de los intereses de la sociedad anónima -que son los intereses que deben siempre prevalecer- y no en función de los intereses de sus accionistas.

- En cuanto a la responsabilidad de los directores, y no obstante que integran un órgano colegiado, viene a ser una responsabilidad personal y no una colectiva, ya que en el propio artículo 177 de la LGS se señala que "los directores" responden ilimitada y solidariamente ante la sociedad, los accionistas y los terceros, por los daños y perjuicios que causen por los acuerdos o actos contrarios a la ley o al estatuto, o por los realizados con dolo, abuso de facultades o negligencia grave. En consecuencia, los directores deben asumir la responsabilidad derivada de su actuación dentro del órgano social, por todos aquellos actos que individualmente realicen o por acuerdos que se adopten con su voto, ya que al momento de producirse la votación perfectamente pueden salvar su responsabilidad por un acto o acuerdo del directorio que consideren que es irre- 
gular o contrario a la ley, pidiendo al efecto que conste en el acta su oposición al acuerdo, y si ello no fuera posible, la misma ley en su artículo 170 les ha concedido un plazo de 20 días útiles después de realizada la sesión, para pedir que se agregue al acta esa oposición.

- Respecto al tema de la regulación de la responsabilidad de los directores, Enrique Elías Laroza ${ }^{1}$, al comentar el artículo 178 de la LGS, incide en el hecho de que la doctrina coincide en que la responsabilidad de los directores debe ser legislada con el máximo rigor, y en que, según el derecho comparado, hay una fuerte inclinación a agravarla (incluso en algunas legislaciones se señalan los casos, formas y causales que la determinan, tanto en el campo civil como en el penal), opinando al respecto que si bien debe evitarse el abuso de poder por parte de los directores a través de normas rigurosas sobre responsabilidad, no se debería propugnar una amplitud excesiva en cuanto a exigencias de responsabilidad que generen incertidumbre e injusticias al propiciar un juzgamiento apresurado, reiterativo y malicioso, por lo que debe encontrarse un adecuado balance como el conseguido en la ley 26887 , donde no se propicia el abuso en las demandas de responsabilidad por causales intrascendentes o de poca importancia, pero sí se abre la opción de exigirles a los directores que respondan por los actos o conductas que originen daños y perjuicios a la sociedad.

1 ELf́AS LAROZA, Enrique. Derecho societario peruano. Tomo 11. Trujillo: Editora Normas Legales, pp. 457 y 458.
- En cuanto a la naturaleza jurídica de la responsabilidad de los directores por el incumplimiento de sus obligaciones, en una primera etapa -ya superada- se sostenía que era asemejable a la responsabilidad contractual del derecho civil, en razón de que los directores ejercen una especie de mandato con representación que sólo puede ser entendido adecuadamente dentro de las relaciones orgánicas en que se encuentra la unidad colegiada o corporativa que es el directorio, y que tal responsabilidad contractual, por tener carácter civil, sólo se configura cuando el incumplimiento de las obligaciones acarrea daños a la sociedad, a sus accionistas o a sus acreedores.

Ahora bien, en relación con la responsabilidad del directorio como unidad jurídica, es necesario referirnos a la posición predominante en la doctrina societaria moderna y que respalda la llamada teoría organicista, la misma que se sustenta destacando la relación existente entre la persona jurídica y el órgano social, que configura una relación orgánica en el sentido de que existe una compenetración intrínseca entre la sociedad y sus órganos que difiere en esencia de las relaciones contractuales entre representante y representado. Esta corriente difiere de las institucionalistas o contractualistas, que restan importancia al directorio como órgano social y sustentan sus posiciones considerando que los directores están relacionados con la sociedad o con sus accionistas en virtud de contratos de mandato o de locación de servicios.

En nuestra opinión, la teoría organicista es la que más se ajusta a la definición de la naturaleza jurídica del directorio, y si bien la LGS no adopta expre- 
samente una posición al respecto, al referirse a que el directorio es un órgano colegiado que tiene las facultades de gestión y de representación legal necesarias para la administración de la sociedad dentro de su objeto, ello nos conduce a establecer que se ubica dentro de la teoría organicista, más aún cuando los actos de comercio llevados a cabo por el directorio son realizados en nombre de la sociedad. Actualmente, dentro de esta moderna corriente se considera que en lugar de tratarse de una responsabilidad contractual se trata de una legal u orgánica, y a esa tendencia consideramos que se ajusta la ley 26887, sin perjuicio de los casos que expresamente señalaremos más adelante, en los cuales se dan supuestos de responsabilidad individual de los directores.

- Respecto a los caracteres de la responsabilidad de los directores, consideramos que cuando el artículo 171 de la ley establece que ellos desempeñan el cargo con la diligencia de un ordenado comerciante y de un representante leal, está sentando las bases para una responsabilidad subjetiva. También, en lo concerniente a los daños y perjuicios causados, cuando en el artículo 177 de la LGS se señala que los directores responden ilimitada y solidariamente ante la sociedad, accionistas y terceros por acuerdos o actos contrarios a la ley, al estatuto o por los realizados con dolo, abuso de facultades y negligencia grave, se alude a una relación de causaefecto, reafirmando con ello el sistema subjetivista, por lo que una condición para el nacimiento de la responsabilidad de los administradores es la existencia de un nexo causal entre sus actos y acuerdos y la existencia efectiva de daños y perjuicios.
Luego de las implicancias mencionadas, pasemos a comentar cada uno de los supuestos de responsabilidad que considera la LGS.

\section{SUPUESTO DEL ARTÍCULO 7 , SOBRE LOS ACTOS ANTERIORES A LA INSCRIPCIÓN DE LA SOCIEDAD}

Este artículo está relacionado con lo que es una especie de convalidación de los actos celebrados con anterioridad a la inscripción en el registro, de la nueva sociedad que se ha constituido, inscripción que, como se sabe, genera el nacimiento de su personalidad jurídica. El artículo 7 en su primera parte establece con claridad los dos requisitos necesarios para esa convalidación: la inscripción de la escritura pública de constitución en el registro y la ratificación por la sociedad dentro de los tres (3) meses siguientes a esa inscripción.

El problema se presenta cuando los requisitos no se cumplen, en cuyo caso la ley dispone que quienes hayan celebrado actos en nombre de la sociedad responden personal, ilimitada y solidariamente ante aquellos con quienes han contratado $y$ ante terceros. Si bien la ley no lo señala, se entiende que la ratificación debe ser expresa; es decir, que son los propios administradores, directores o gerentes en su caso los que deben propiciar que tal ratificación se realice, lo cual en la práctica hay que reconocer que no sucede.

En el caso particular de las sociedades anónimas, existe en la LGS el artículo 71, que está referido específicamente a quienes son fundadores de la sociedad anónima, de forma tal que si ellos han actuado en nombre de la sociedad, quedan liberados al vencimiento del plazo de tres meses antes indicado; señalando el mismo artícu- 
lo que, a falta de pronunciamiento expreso, se presume que tales actos y contratos han sido tácitamente ratificados. En otras palabras, para quienes han tenido la calidad de socios fundadores la ley ha dado una solución con la ratificación tácita o presunta, y para quienes no, no se ha pronunciado expresamente, lo cual significa que si fuere el caso que los ya designados directores en la escritura pública de constitución han actuado en nombre de la sociedad sin ser accionistas-fundadores de la misma, asumen responsabilidad personal, solidaria e ilimitada frente a aquellos con quienes han contratado y frente a terceros.

\section{SUPUESTO DEL ARTÍCULO 12, SOBRE RESPONSABILIDAD POR LOS ACTOS ULTRA-VIRES}

Este artículo está directamente relacionado con el objeto social y los alcances de la representación. El objeto social constituye el marco de referencia para la constitución y gestión de los órganos sociales y de los administradores. En el caso específico de la sociedad anónima, según el artículo 172 de la LGS el directorio tiene las facultades de gestión y de responsabilidad legal necesarias para la administración de la sociedad dentro de su objeto. Una vez delimitado el objeto social elegido e incorporado en el pacto social y en el estatuto, será posible apreciar, como lo señala el artículo 11 de la LGS, aquellos actos que pueden considerarse incluidos en dicho objeto por estar relacionados con él o porque coadyuvan a la realización de sus fines al existir un nexo o vinculación que así lo permite. No obstante la impermeabilidad y relativa flexibilidad de esta última norma, siempre habrá un marco de referencia que en definitiva resulta fundamental para, por un lado, juzgar y evaluar la responsabilidad de los administradores, directores y gerentes, y por otro, identificar los actos y contratos que exceden el objeto social, llamados actos ultra-vires, así como las responsabilidades que se derivan de quienes los han celebrado.

La LGS en su artículo 12 y en lo que se refiere a los actos ultra-vires, lo que ha querido es proteger a los terceros de buena fe, estableciendo en su primer párrafo que la sociedad queda obligada frente a aquellos con quienes ha contratado y frente a terceros de buena fe, por los actos de sus representantes celebrados dentro de los límites de las facultades que les haya conferido, aunque esos actos comprometan a la sociedad, negocios u operaciones no comprendidos dentro de su objeto social. Lo que es más importante: en su segundo párrafo, para compensar la responsabilidad que ha tenido que asumir la sociedad, establece que los socios o administradores -es decir, los directores y gerentes de las sociedades anónimas-, según el caso, responden frente a ella por los daños y perjuicios que haya experimentado como consecuencia de acuerdos adoptados con su voto y en virtud de los cuales se pudiera haber autorizado la celebración de actos que extralimitan su objeto social, sin perjuicio de la responsabilidad penal que pudiese corresponderles. En otras palabras, lo que la ley ha querido en este artículo es establecer la responsabilidad, al interior de la sociedad, de quienes han excedido el objeto social, y no perjudicar a los terceros que de buena fe han contratado con ésta. 
3. SUPUESTO DEL ARTICULO 18, SOBRE RESPONSABIIIDAD POR LA NO INSCRIPCIÓN DE LA SOCIEDAD

Este artículo señala expresamente que los otorgantes o administradores -es decir, los directores y gerentes, tratándose de sociedades anónimas-, según el caso, responden solidariamente por los daños y perjuicios que ocasionen como consecuencia de la mora en que incurran en el otorgamiento de las escrituras públicas u otros instrumentos requeridos, o en las gestiones necesarias para la inscripción oportuna de los actos y acuerdos que por su naturaleza son inscribibles.

En consecuencia, del propio texto de la ley se infiere que la responsabilidad de los otorgantes y administradores es solidaria y opera a favor de cualquier persona natural o jurídica que se haya perjudicado por la demora o retraso en el otorgamiento o inscripción de un acto o acuerdo de la sociedad. En nuestra opinión, en el caso específico de la sociedad anónima y habiéndose determinado la responsabilidad de los directores -0 de alguno en particular, que de manera especial hubiera recibido una delegación expresa-, estarían legitimados, para accionar contra éstos, en primer lugar la propia sociedad; en segundo, los accionistas individualmente, $\mathrm{y}$ en tercer lugar los acreedores o terceros que hubieran sufrido daños y perjuicios.

\section{SUPUESTO DEL ARTÍCULO 24, SOBRE LOS GASTOS NECESARIOS PARA LA CONSTITUCIÓN DE LA SOCIEDAD}

Innovando, este artículo de la LGS faculta a los administradores de una socie- dad en formación, bajo su responsabilidad personal, a atender gastos que fueren necesarios para ella, una vez otorgada la escritura pública de constitución y aun cuando no hubiese culminado el proceso de inscripción de la sociedad en el registro, utilizando al efecto los aportes dinerarios que se hubiesen depositado en una entidad del sistema financiero nacional. Esta norma es perfectamente entendible tratándose de sociedades de cierto volumen de operaciones, que se ven urgidas de realizar inversiones o gastos que no pueden ser solventados con los recursos propios de los fundadores. Ahora, bajo responsabilidad de los administradores, se puede disponer de esos fondos.

Este supuesto de responsabilidad está estrechamente vinculado con los supuestos de responsabilidad comentados en relación con los artículos 7 y 18 de la LGS.

\section{SUPUESTO DEL ARTÍCULO 40 , RELACIONADO CON LA RESPONSABILIDAD DE LOS ADMINISTRADORES EN LOS CASOS DE REPARTO INDEBIDO DE UTILIDADES}

De gran importancia, este artículo indica en qué casos y bajo qué circunstancias las sociedades pueden distribuir utilidades, señalando, como normas fundamentales, que las sumas que se repartan, en ningún caso pueden exceder el monto de las utilidades que realmente se obtengan, y que si se hubiere perdido en ejercicios económicos anteriores una parte del capital, no se pueden distribuir utilidades en tanto dicha parte del capital no sea reintegrada o éste no fuere reducido en la cantidad correspondiente. 
Adicionalmente, el artículo establece sanciones para los casos en que se incurra en infracción de estas normas fundamentales y, en ese sentido, señala que tanto la sociedad como sus acreedores pueden repetir por cualquier distribución de utilidades hecha en contravención de tales normas, accionando contra los socios que las hayan recibido o, alternativamente, exigiendo su reembolso a los administradores que las hubiesen pagado; y fija para estos últimos responsabilidad solidaria.

En relación con los accionistas, el tratamiento de la ley hace diferencias: cuando se trata de accionistas que actúan con mala fe, son de aplicación las acciones mencionadas; pero tratándose de accionistas que hubiesen actuado de buena fe, sólo estarán obligados a compensar las utilidades recibidas con las que les correspondan en los ejercicios siguientes o con la cuota de liquidación que pudiera tocarles.

En lo que se refiere a la responsabilidad solidaria de los administradores -es decir, responsabilidad de los directores y gerentes en el caso de sociedades anónimas-, ella opera exclusivamente cuando se hubiere producido colusión o connivencia con los accionistas, para falsear los estados financieros y propiciar con ello un reparto indebido de utilidades.

\section{SUPUESTO DE RESPONSABILIDAD DEL ARTÍCULO 76, SOBRE REVISIÓN DEL VALOR DE LOS APORTES NO DINERARIOS}

Esta norma establece el procedimiento relativo a la revisión del valor de los aportes no dinerarios -necesaria, pues la asignación de valores sobrevaluados genera perjuicios a la sociedad, a los accionistas y a los terceros-, señalando que dentro del plazo de 60 días contados desde la constitución de la sociedad o el pago del aumento de capital, el directorio está obligado a revisar la valorización de aquellos aportes.

Al obligar al directorio a dicha revisión, el legislador ha dejado de lado mecanismos utilizados en otras legislaciones, como el empleo obligatorio de peritos oficiales o las tasaciones encomendadas a entidades estatales. Esta revisión es independiente del informe de valorización que de acuerdo con el artículo 27 de la LGS debe insertarse en la escritura pública donde conste el aporte no dinerario, y lo que se pretende con ella es confirmar que los valores asignados a los aportes sean lo más ajustados a los valores del mercado en ese momento.

El artículo también dispone que, transcurrido el plazo de 60 días, los accionistas tienen un plazo de 30 días adicionales para solicitar que se compruebe judicialmente la valorización de los aportes no dinerarios. En nuestra opinión, este plazo le permite al accionista no sólo contrastar o confrontar el resultado de la revisión efectuada por el directorio, sino solicitarla cuando éste ha omitido realizarla, como un mecanismo útil para corregir la posible sobrevaluación de esos aportes supliendo la omisión o negligencia de aquél.

Por otro lado, este artículo no establece cuál es específicamente el tipo de responsabilidad que asume el directorio en los casos en que omite llevar a cabo la revisión o actúa con arbitrariedad. En nuestra opinión, se trata de un claro supuesto de responsabilidad frente a la sociedad, los accionistas y los terceros, por los daños y perjuicios que se irroguen debido a esa omisión o arbitrariedad. 
7. SUPUESTO DEL ARTÍCULO 117 , POR NO CONVOCATORIA A JUNTA GENERAL A SOLICITUD DE LOS ACCIONISTAS

Este artículo establece que cuando uno o más accionistas que representen no menos del $20 \%$ de las acciones suscritas con derecho a voto, soliciten notarialmente la celebración de la junta general, el directorio debe publicar el aviso de convocatoria dentro de los 15 días siguientes a la recepción de la solicitud respectiva, el que deberá indicar los asuntos que los solicitantes propongan tratar. Señala, asimismo, que la junta general debe ser convocada para celebrarse dentro de un plazo de 15 días a partir de la fecha de la publicación de ese aviso.

Estamos aquí ante un caso de convocatoria excepcional a pedido de los accionistas, pues normalmente es el directorio quien está legitimado, en su calidad de órgano de administración, para convocar a junta si lo considera necesario para el interés social (es claro que la junta general no puede autoconvocarse, pues ello colisionaría frontalmente con la administración de la sociedad, dejando a salvo, claro está, el caso de las juntas universales). En el supuesto mencionado, la iniciativa de la convocatoria parte de los propios accionistas, y el mismo artículo establece que si la solicitud respectiva fuese denegada por el directorio o por la gerencia general (en el caso de las S.A.C.) o transcurriesen más de 15 días de presentada $\sin$ efectuarse la convocatoria, los accionistas que acrediten reunir el porcentaje exigido de acciones podrán solicitar al juez de la sede de la sociedad que ordene la convocatoria por el proceso no contencioso. En caso de que el juez amparase la solicitud, ordenará la convocatoria, señalará el lugar, día y hora de la reunión, su objeto, quién la presidirá y qué notario dará fe de los acuerdos.

En nuestra opinión, en el artículo existe un vacío al no precisar qué tipo de responsabilidad recae en el directorio cuando, de manera arbitraria y/o abusiva, no le da trámite a un pedido de convocatoria hecho por los accionistas, obligándoles a recurrir al juez. En tal situación, siempre existe la pretensión individual de responsabilidad de la cual gozan los accionistas para accionar contra los directores que lesionen directamente sus intereses, pretensión que se encuentra regulada en el artículo 182 de la LGS.

\section{SUPUESTO DEL ARTÍCULO 162, RELATIVO A IMPEDIMENTOS SOBREVINIENTES}

Hemos insistido en la importancia que tiene el directorio como órgano de administración de la sociedad y en la de las condiciones y cualidades de quienes son elegidos sus miembros. En general, en todas las legislaciones societarias se contemplan, por un lado, las calidades que deben reunir las personas designadas y la forma como deben desempeñar el cargo, y por otro, las prohibiciones, incompatibilidades e impedimentos para su ejercicio. No se trata de analizar cada uno de los incisos específicos del artículo 161 de la LGS, pero sí de poner énfasis especial en el contenido del artículo 162 cuando establece que si alguna persona natural propuesta para ser director está incursa en alguno de los impedimentos del artículo 161 , no puede aceptar el cargo, por impedimento preexistente, o debe renunciar inmediatamente a él, si el impedimento fuere sobreviniente. De no proceder como 
se señala, el director infractor responderá por los daños y perjuicios que sufra la sociedad y será removido de inmediato por la junta general a solicitud de cualquier director o accionista. La parte final del artículo 162 establece, asimismo, que en tanto no se reúna la junta general para la remoción aludida, el propio directorio puede proceder a efectuarla.

En el supuesto que comentamos, es evidente la responsabilidad individual del director incurso en cualquiera de los impedimentos. Y si, efectivamente, se demuestra la generación de daños y perjuicios, será la sociedad la que podrá iniciar la pretensión social de responsabilidad a que se refiere el artículo 181 de la LGS, para de esa forma obtener un resarcimiento.

\section{SUPUESTO DEL ARTÍCULO 171, SOBRE EL EJERCICIO DEL CARGO DE DIRECTOR}

Cuando este artículo prescribe que los directores deben desempeñar el cargo con la diligencia de un ordenado comerciante y de un representante leal, su propósito es establecer un patrón de conducta con la finalidad de que cumplan a cabalidad su rol dentro del órgano de administración de la sociedad, de forma tal que con una actuación prudente, profesional y diligente, realicen todos los actos propios del objeto social.

El segundo párrafo del artículo obliga a los directores a guardar reserva respecto de los negocios de la sociedad y la información social a que tengan acceso, aún después de cesar en sus funciones. Consideramos, por un lado, que se debió fijar un plazo límite para este deber de reserva o, en todo caso, establecer distintos criterios en función del tipo de negocio o actividad que realiza la sociedad; y por otro, que la norma es necesaria a fin de evitar que los directores causen daño a la sociedad debido a la divulgación de información privilegiada o reservada. Así, si se generan daños por el resquebrajamiento de este deber de reserva y confidencialidad, el director infractor incurrirá en una causal de responsabilidad frente a la sociedad, accionistas y terceros, y su caso se encuadrará dentro de los alcances del artículo 177 de la LGS.

\section{SUPUESTO DE RESPONSABILIDAD DEL ARTÍCULO 175, SOBRE INFORMACIÓN FIDEDIGNA}

Este artículo impone al directorio la obligación de proporcionar a los accionistas y al público en general, las informaciones suficientes, fidedignas y oportunas que la ley determine respecto de la situación legal, financiera y económica de la sociedad, con lo cual se garantiza a los terceros que se vinculen con la sociedad, el conocimiento veraz respecto de la marcha de ésta. Consideramos que lo más importante es que el órgano de administración sepa discriminar y diferenciar respecto a qué tipo de información es conveniente o adecuado divulgar, y qué otra información debe ser considerada reservada o confidencial, en función de los intereses de la sociedad.

Respecto, específicamente, a las sociedades anónimas abiertas, el artículo 261 de la LGS consagra el derecho de los accionistas que representen no menos del 5\% del capital pagado, a solicitar información, la que debe ser proporcionada por el directorio siempre que no se trate de hechos reservados o de asuntos cuya divulgación pueda ocasionar daño a la 
sociedad, debiendo Conasev decidir en definitiva sobre el contenido de la solicitud y si procede o no suministrar la información solicitada.

Es importante señalar, al respecto, que la norma establece que la información debe ser suficiente, fidedigna y oportuna. De no ofrecerla así, los directores serán responsables civil y penalmente por los daños y perjuicios que ocasionen a la sociedad.

\section{SUPUESTO DE RESPONSABILIDAD DEL ARTÍCULO 176, POR EL INCUMPLIMIENTO DE LAS OBLIGACIONES EN CASO DE PÉRDIDAS}

En su primer párrafo, este artículo obliga al directorio a convocar de inmediato a la junta general si advierte que los estados financieros correspondientes al ejercicio o a períodos menores arrojan perdidas de la mitad o más del capital, o si ellas debieran presumirse.

En cuanto al segundo párrafo -cuyos efectos, nuevamente, por ley 27610 , han quedado en suspenso hasta el 31 de diciembre de 2003-, se señala que si el activo de la sociedad no fuese suficiente para satisfacer el pasivo o si tal insuficiencia debiera presumirse, el directorio deberá convocar a junta general para informarle la situación y, dentro de los 15 días siguientes a la fecha de esta convocatoria, debe llamar a los acreedores y solicitar, si fuere el caso, la declaración de insolvencia de la sociedad.

En nuestra opinión, este artículo consagra en su contenido integral las obligaciones más importantes que asumen los directores de una sociedad anónima, que lo son por estar directamente relacionadas con su situación económica y financiera y tener que ver directamente con su continuidad y supervivencia. Los supuestos a los que se refiere el artículo son situaciones de extrema gravedad, que exigen que el directorio actúe con la máxima diligencia y eficiencia. Si no lo hace, adquiere graves responsabilidades, tipificándose una clara situación de negligencia grave que hace pasibles a sus integrantes de responsabilidad civil y penal.

\section{SUPUESTOS DE RESPONSABILIDAD ILIMITADA Y SOLIDARIA DEL ARTÍCULO 177}

Según este artículo, los directores responden ilimitada y solidariamente ante la sociedad, los accionistas y los terceros, por los daños y perjuicios que causen por acuerdos o actos contrarios a la ley o al estatuto, o por los realizados con dolo, abuso de facultades o negligencia grave. Señala también que es responsabilidad del directorio el cumplimiento de los acuerdos de la junta general, salvo que ella disponga algo distinto para determinados casos particulares.

Este artículo es de singular importancia: en primer lugar, precisa cómo responden los directores; en segundo, frente a quién responden; y tercero, precisa las causales y razones de dicha responsabilidad.

Tratándose de actos o acuerdos contrarios a la ley o al estatuto, los directores son personalmente responsables por no cumplir las obligaciones señaladas por éstos, en los acuerdos que adopten o los actos que realicen. Es importante advertir, al respecto, que si bien la ley señala de manera expresa los supuestos en los cuales se genera responsabilidad para los directores, hay numerosos supuestos en los cuales se 
establecen las funciones y atribuciones del directorio, pero no se señalan las responsabilidades que asumen si no las cumplen, con lo cual se configuran supuestos de responsabilidad tácita, como por ejemplo: el incumplimiento del registro de los convenios a que se refiere el artículo 8 de la LGS, la no convocatoria oportuna a juntas, la inacción en la cobranza de los dividendos pasivos, la no emisión de acciones y sus correspondientes certificados, y muchos otros casos más.

En cuanto a la presencia de dolo, dependerá del caso concreto su calificación y tipificación en el ámbito civil o penal, debiéndose señalar que es requisito indispensable que la situación dolosa afecte a la sociedad, a sus accionistas o a terceros acreedores.

En lo relativo al abuso de facultades, son muchos los casos que se pueden configurar, siendo el más común el aprovechamiento indebido y personalizado de los recursos propios de la sociedad.

Respecto a la negligencia grave, se requiere que la actuación de los directores adolezca de falta de diligencia y de profesionalidad, lo que deberá ser analizado en cada caso particular, teniendo en cuenta la naturaleza de los negocios de la sociedad y la magnitud de los daños.

Finalmente, en cuanto a la responsabilidad del directorio de cumplir con los acuerdos de la junta general, ello se deriva de su naturaleza de órgano de administración, subordinado a la segunda, que es el órgano de mayor jerarquía; razón por la cual es importante que se haya incorporado en la ley el incumplimiento de los acuerdos de la junta general como causal de responsabilidad, más aún cuando por tal incumplimiento se pueden generar daños y perjuicios a la sociedad, a los accionistas o a terceros acreedores.

\section{SUPUESTO DE RESPONSABILIDAD POR OMISIÓN DE DENUNCIA}

El artículo 177 también señala, en su último párrafo, que los directores son solidariamente responsables, conjuntamente con los directores que los han precedido, por las irregularidades que éstos hubieran cometido si, conociéndolas, no las denunciaron por escrito a la junta general. Al respecto, consideramos que esta omisión de denuncia hace al director cómplice y responsable de dichas irregularidades, por ser su obligación revelarlas y divulgarlas a la junta general, y que este supuesto ha debido ser más específico y establecer plazos máximos para cumplir con tal obligación, ya que, de lo contrario, su responsabilidad podría extenderse por un período muy prolongado.

\section{SUPUESTOS DE RESPONSABIIIDAD DEL ARTÍCULO 179, SOBRE CONTRATOS, CRÉDITOS, PRÉSTAMOS O GARANTÍAS}

El artículo 179 de la LGS establece reglas precisas, requisitos y limitaciones para el otorgamiento de contratos, créditos, préstamos o garantías por parte de la sociedad. Dichas condiciones o requisitos son los siguientes:

- Si bien un director puede celebrar contratos con la sociedad, ellos sólo pueden versar sobre aquellas operaciones que normalmente ésta realice con terceros, y siempre que se concierten en las condiciones de mercado.

- La sociedad sólo puede conceder créditos o préstamos a los directores, u otorgar garantías a su favor, cuando se trate de aquellas operaciones que normal- 
mente celebre con terceros. Aun cuando la ley no lo mencione expresamente, entendemos que lo que el legislador ha querido decir es que estos créditos o préstamos, en el supuesto de que se otorguen, se deben dar bajo las mismas condiciones económicas que rigen para los créditos otorgados a particulares.

- Excepcionalmente, en caso de que se trate de otorgar a los directores créditos, préstamos o garantías que no reúnen los requisitos anteriormente mencionados, podrá hacerse siempre y cuando el directorio los apruebe con el voto de al menos $2 / 3$ de sus miembros, entendiendo al efecto que no se trata de $2 / 3$ del quórum reunido en el directorio, sino del número legal de directores.

El artículo 179 señala que estas reglas son aplicables cuando se trata de directores de empresas vinculadas, y de los cónyuges, descendientes, ascendientes y parientes dentro del tercer grado de consanguinidad o segundo de afinidad de los directores de la sociedad y de los directores de la empresa vinculada. Interesa destacar que en su parte final el artículo señala puntualmente que los directores son solidariamente responsables ante la sociedad y los terceros acreedores por los contratos, créditos, préstamos o garantías celebrados u otorgados con infracción de las reglas establecidas, pero omite señalar que también lo sean ante los accionistas, no guardando por ello coherencia con lo establecido en el artículo 177 de la LGS.

\section{SUPUESTO DE RESPONSABILIDAD DEL ARTÍCULO 180, CUANDO EXISTE CONFLICTO DE INTERESES}

Este artículo expresa que los directores no pueden adoptar acuerdos que en lugar de cautelar el interés social cautelen sus propios intereses o los de terceros relacionados, ni usar en beneficio propio o de terceros las oportunidades comerciales o de negocios de que tuvieran conocimiento en razón de su cargo. En otras palabras, debe prevalecer el interés social sobre cualquier interés particular de los directores o de sus relacionados, y por ello los directores no pueden aprovecharse indebidamente de la información privilegiada que llega a su conocimiento y que está relacionada con los negocios de la sociedad.

Adicionalmente, el artículo establece que los directores no pueden participar por cuenta propia o de terceros en actividades que compitan con la sociedad, sin el consentimiento expreso de ésta. En este aspecto, omite señalar cuál es la forma a través de la cual se debe dar ese consentimiento, presumiéndose al efecto que éste debería ser materia de un acuerdo de la junta general.

El artículo también expresa que si el director en algún asunto tiene intereses contrarios a los de la sociedad, debe manifestarlo y abstenerse de participar en la deliberación y resolución concerniente a dicho asunto.

Pero lo más importante del citado artículo es el párrafo final, donde se señala que el director que contravenga las disposiciones del artículo es responsable de los daños y perjuicios que cause a la sociedad, pudiendo ser removido por el propio directorio o por la junta general a propuesta de cualquier accionista o director; siendo innovador que la remoción del director incurso en este supuesto la puede hacer el propio directorio, o alternativamente, la junta general, a propuesta de cualquier accionista o director. Obviamente, en estos casos la sociedad puede iniciar la acción social de responsabilidad, regulada por el artículo 181 de la LGS, siendo que el 
acuerdo para iniciar dicha acción puede ser adoptado aunque no haya sido materia de la convocatoria.

\section{SUPUESTO DE RESPONSABILIDAD DEL ARTÍCULO 191, SOBRE LA RESPONSABIIDAD SOLIDARIA DEL GERENTE CON LOS DIRECTORES}

Conforme lo establece el artículo 152 de la LGS, la administración de una sociedad anónima está a cargo del directorio y de uno o más gerentes, salvo el caso de una sociedad anónima cerrada, que puede tener un régimen especial. De acuerdo con el artículo 191 de la misma ley, el gerente es responsable solidariamente, con los miembros del directorio, cuando participe en actos que den lugar a responsabilidad de éstos o cuando, conociendo la existencia de esos actos, no informe sobre ello al directorio o a la junta general.

Este supuesto de responsabilidad solidaria es perfectamente entendible en razón de que es el gerente quien conoce todos los aspectos relacionados con la actividad cotidiana de la sociedad, es el interlocutor válido frente al directorio y normalmente está a cargo de todo lo que se va a tratar en la agenda correspondiente, suministrando la información que sea necesaria; de tal modo que es muy difícil que no conozca los temas que se ventilan en las sesiones de directorio (debe tenerse en cuenta, sin embargo, que aunque el inciso 3 del artículo 191 señala que el gerente tiene la atribución de asistir con voz pero sin voto a las sesiones del directorio, se ha previsto como excepción que este último pueda acordar sesionar de manera reservada, sin su presencia).

Conocida directa o indirectamente una irregularidad en la que se haya incurrido en la administración de la sociedad, en cualquiera de los supuestos, ello obliga al gerente a denunciarla ante el directorio o la junta general, aun cuando no esté directamente vinculado con el acto u omisión que genera la irregularidad. De lo contrario, incurre en responsabilidad solidaria.

\section{SUPUESTO DE RESPONSABILIDAD DEL ARTÍCULO 218, SOBRE DEVOLUCIÓN DE APORTES ANTES DEL PLAZO}

Este artículo de la LGS está incluido dentro del título III de la sección quinta, del libro II de la ley, relativa a la reducción del capital social, donde se establece que esta reducción podrá ejecutarse de inmediato cuando tenga por finalidad restablecer el equilibrio entre el capital y el patrimonio neto, o por cualquier otro motivo que no importe devolución de aportes ni exención de deudas de los accionistas, ya que en estos dos últimos casos tal reducción sólo puede llevarse a cabo luego de transcurridos treinta (30) días desde la última publicación del aviso a que se refiere el artículo 207.

$\mathrm{Al}$ respecto, es pertinente mencionar que todo acuerdo de reducción de capital debe expresar la cifra en que se reduce, la forma como se realiza, los recursos con cargo a los cuales se efectúa y el procedimiento por el cual se lleva a cabo, debiéndose publicar un extracto del acuerdo por tres veces, con intervalo de cinco días.

El último párrafo del artículo 218 señala que si se efectúa una devolución de aportes o una condonación de dividendos pasivos antes del vencimiento del plazo de 30 días computables desde la publicación del último aviso, las entregas que se hagan no serán oponibles al acreedor, y los direc- 
tores serán solidariamente responsables con la sociedad frente al acreedor que ejerciera el derecho de oposición normado por el artículo 210. Adviértase que en este supuesto de responsabilidad solidaria, a diferencia de los otros casos, se equipara en el mismo nivel de responsabilidad a la sociedad con sus directores.

\section{SUPUESTO DE RESPONSABILIDAD DEL ARTÍCULO 225, RELACIONADO CON LA APROBACION DE LA MEMORIA Y LOS ESTADOS FINANCIEROS DE LA SOCIEDAD}

Según el artículo 221 de la LGS, finalizado el ejercicio económico, el directorio debe formular la memoria, los estados financieros y la propuesta de las utilidades, si es que las hubiere, documentos de los que debe resultar, con claridad y precisión, la situación económica y financiera de la sociedad, el estado de sus negocios y los resultados obtenidos en el ejercicio vencido.

Ahora bien, el artículo 225 señala que la aprobación, por la junta general, de la memoria y los estados financieros no importa el descargo de las responsabilidades en que pudiesen haber incurrido los directores, con lo cual nuestra ley ha tomado posición contraria a la legislación comparada, para la cual la aprobación de cuentas significa automáticamente el descargo de las responsabilidades de los administradores. Es decir, aun con la aprobación de dichos documentos siempre queda a salvo la acción social de responsabilidad regulada por el artículo 181, con la posibilidad de que los accionistas y los acreedores emplacen judicialmente a los directores por las responsabilidades en que hayan incurrido, y también quedan a salvo las acciones individuales de responsabilidad reguladas por el artículo 182, de acuerdo al cual los socios y terceros pueden interponer pretensiones de indemnización contra los directores que hayan lesionado directamente sus intereses.

\section{SUPUESTO DE RESPONSABIIIDAD DE LOS DIRECTORES ESTABLECIDO EN EL ARTÍCULO 348, POR LA FUSIÓN}

El artículo 346 de la LGS establece, como una innovación muy necesaria, que el directorio de cada una de las sociedades que pretenden la fusión, debe aprobar con el voto favorable de la mayoría de sus miembros el texto del proyecto de fusión. Por su parte, el artículo 348 señala que la aprobación del proyecto por el directorio implica la obligación de abstenerse de realizar o ejecutar cualquier acto o contrato que pueda comprometerlo o alterar significativamente la relación de canje de las acciones o participaciones, hasta la fecha de realización de las juntas generales o asambleas de las sociedades participantes convocadas para pronunciarse sobre la fusión.

La obligación establecida en el artículo 348 genera responsabilidad para los directores que la incumplan, y tiene como propósito, en nuestra opinión, impedir que el órgano de administración de la sociedad obstaculice la fusión que en su momento debe acordar la junta general, ya que él es el responsable de organizar y manejar una reorganización societaria de tanta trascendencia.

Es importante señalar, asimismo, que en las juntas generales es obligación de los directores informar, antes de la adopción del acuerdo, sobre cualquier variación significativa experimentada por el patrimonio de las sociedades participantes, desde la 
fecha en que se estableció la relación de canje, y si a pesar de ello el acuerdo se adopta, éste deberá contener de manera expresa las modificaciones del proyecto inicialmente aprobado.

\section{SUPUESTO DE RESPONSABIIIDAD DE LOS DIRECTORES ESTABLECIDO EN EL ARTÍCULO 373, POR LA ESCISIÓN}

La fusión y la escisión se han regulado en la LGS de manera similar, aun cuando, evidentemente, se trata de dos figuras diferentes de reorganización societaria.

En el caso de la escisión, también el proyecto debe ser aprobado por el directorio $\mathrm{y}$, como en la fusión, a partir de su aprobación los directores tienen la obligación de abstenerse de realizar cualquier acto que pueda comprometer su aprobación por la junta o alterar significativamente la relación de canje de las acciones o participaciones, hasta que la junta general apruebe la escisión. Igualmente, existe en el caso de la escisión la obligación del directorio de informar a la junta, antes de la adopción del acuerdo de escisión, de cualquier variación significativa experimentada en el patrimonio de las sociedades participantes, desde la fecha en que se estableció la relación de canje en el proyecto de escisión.

\section{SUPUESTO DEL ARTÍCULO 424, SOBRE SOCIEDADES IRREGULARES}

La ley anterior se ocupaba de este tema en el título único de la sección quinta del libro III, entre los artículos 385 y 397 . En la nueva ley se han introducido importantes innovaciones, que detallamos en los párrafos que siguen.

El artículo 423 hace una importante distinción cuando señala las causales de irregularidad; podría decirse que introduce, por primera vez, dos diferentes tipos de sociedades irregulares: las primeras, a las que podríamos denominar sociedades irregulares de hecho, serían las que no se han constituido e inscrito conforme a la ley, o aludirían a la situación de hecho que resulta de que dos o más personas actúan de manera manifiesta como sociedad, sin haberla constituido e inscrito; y las segundas, a las que llamaríamos sociedades irregulares de derecho, serían las que cuando menos han celebrado el pacto social.

Las primeras son sociedades informales que realizan actividades económicas sin haber iniciado siquiera el proceso de constitución social, incluso con la clara intencionalidad de no hacerlo nunca; sin embargo, contratan con terceros bajo la apariencia de una sociedad. Se les llama también sociedades irregulares de origen, asumiendo, los que participan en ella, plena y total responsabilidad personal, solidaria e ilimitada.

Respecto de las sociedades irregulares de derecho, el artículo 423 distingue seis diferentes supuestos, siendo los cuatro primeros acertadas novedades legislativas:

- Cuando transcurren 60 días desde que los socios fundadores han firmado el pacto social, sin haber solicitado el otorgamiento de escritura de constitución.

- Si han transcurrido 30 días desde que la asamblea designó al o a los firmantes para otorgar la escritura pública, sin que éstos hayan solicitado su otorgamiento. Este supuesto se puede presentar únicamente en el proceso de constitución por oferta a terceros regulado en el artículo 56 y siguientes de la 
ley, ya que el artículo 66 dispone que, dentro de este plazo, la persona o personas designadas para otorgar la escritura pública deben hacerlo con sujeción a los acuerdos adoptados por la asamblea.

- Cuando transcurren más de 30 días desde que se otorgó la escritura pública de constitución, sin que se haya solicitado su inscripción en el registro, plazo que coincide con el artículo 16 de la ley.

- Cuando transcurren 30 días desde que quedó firme la denegatoria a la inscripción, formulada por el registro.

- Cuando la sociedad se ha transformado sin observar las disposiciones de la ley, causal que sí estaba incluida dentro del artículo 385 de la ley anterior.

- Cuando la sociedad continúa en actividad, no obstante haber incurrido en la causal de disolución prevista en la ley, el pacto social o el estatuto, causal que también se encontraba prevista en el artículo 385 de la ley anterior.

Se ha regulado de manera sistemática, cambiándose el orden de los temas referidos a las sociedades irregulares, $y$, en ese sentido, antes de normar la forma como se regularizan o disuelven las sociedades irregulares, se puntualizan en el artículo 424 los efectos que se derivan de la irregularidad y en el artículo 425 la obligación de los socios de aportar.

En efecto, el artículo 424 precisa que los administradores, representantes $y$, en general, quienes se presenten ante terceros actuando en nombre de la sociedad irregular, son personal, solidaria e ilimitadamente responsables por los contratos y los actos jurídicos realizados desde que se produjo la irregularidad (esta norma está referida a las irregularidades producidas por causales sobrevinientes, que afectan el futuro de sociedades debida y formalmente constituidas, debiéndose destacar que la redacción ahora es más técnica, ya que habla de "contratos y actos jurídicos" en lugar de "operaciones practicadas").

Adicionalmente, en el mismo artículo se precisa que las responsabilidades establecidas en él comprenden el cumplimiento de la respectiva obligación, así como, en su caso, la indemnización por los daños y perjuicios ocasionados por actos y omisiones que lesionen directamente los intereses de la sociedad, de los socios o de terceros, pudiendo incluso los afectados plantear simultáneamente sus pretensiones por la vía del proceso abreviado.

Para las sociedades irregulares de origen, la responsabilidad recae en los socios.

\section{SUPUESTOS DE RESPONSABILIDAD DE LOS DIRECTORES POR LA SEGUNDA DISPOSICIÓN TRANSITORIA DE LA LEY GENERAL DE SOCIEDADES}

El 9 de diciembre de 1997 fue publicada en el diario oficial El Peruano la ley 26887, por medio de la cual se aprobó la nueva Ley General de Sociedades (LGS), norma que entró en vigencia a partir del 1 de enero de 1998. Como hemos mencionado en el apartado anterior, el artículo 424 de la LGS expresa que los administradores, representantes y, en general, quienes se presenten ante terceros actuando a nombre de la sociedad irregular, se considerarán ilimitada, personal y solidariamente responsables, civil y penalmente, por los contratos y actos jurídicos realizados desde que se produjo la irregularidad.

Según la primera disposición transitoria de la LGS, las sociedades debían adecuar su pacto social y su estatuto a las disposi- 
ciones de la ley, en la oportunidad de la primera reforma que efectuaran a los mismos o, a más tardar, dentro de los 270 días siguientes a la fecha de su entrada en vigencia. Dicho acto se tendría por cumplido con la suscripción de la escritura pública; sin embargo, su eficacia se encontraría sujeta a su inscripción en los registros públicos.

Posteriormente, mediante ley 26977, publicada en el diario oficial El Peruano el 19 de setiembre de 1998 , se modificó la primera disposición transitoria de la LGS, ampliando el plazo para la adecuación de todas las sociedades a la LGS hasta el 31 de diciembre de 1999. Luego, la ley 27219 , publicada en el diario oficial El Peruano el 12 de diciembre de 1999, modificó la misma disposición transitoria y amplió el plazo de adecuación hasta el 31 de diciembre de 2000. Finalmente, el mismo plazo fue ampliado, nuevamente, por la ley 27388, publicada en el diario oficial $E l$ Peruano el 30 de diciembre de 2000, hasta el 31 de diciembre de 2001.

Ahora, mediante la ley 27673, publicada el 21 de febrero del presente año en el diario oficial El Peruano, se ha establecido la posibilidad de regularizar a aquellas sociedades que no hayan adecuado oportunamente su estatuto social a las disposiciones de la Ley General de Sociedades -ley 26887-, liberándolas de los efectos derivados de su condición de irregulares dispuestos en la segunda disposición transitoria y en los artículos 424 al 432 de la LGS.

En este orden de ideas, la norma bajo comentario dispone expresamente en su artículo único que las sociedades que adecuen su pacto social y estatuto a las disposiciones de la LGS no requerirán de convocatoria judicial para su regularización, contra lo señalado en el artículo 426 de la ley, que consagraba las dos vías legales derivadas de su condición de irregulares: la primera, referente a su regularización mediante el acuerdo de junta general de accionistas convocado judicialmente por cualquier socio según lo estipulado en el artículo 119 de la ley; y la segunda, relativa a la disolución y liquidación de la sociedad. 